\title{
Identification and molecular characterization of Brucella abortus and Brucella melitensis isolated from milk in cattle in Azerbaijan
}

\author{
Jeyhun Aliyev ${ }^{1}$, Mahnur Alakbarova ${ }^{2}$, Aytan Garayusifova ${ }^{3}$, Asaf Omarov${ }^{4}$, Saida Aliyeva ${ }^{5}$, David Fretin ${ }^{6}$ and \\ Jacques Godfroid ${ }^{7^{*}}$ (D)
}

\begin{abstract}
Background: Azerbaijan currently ranks thirteenth in global incidence of human brucellosis, with an estimated annual incidence through 2000 at over 50 cases per million. Brucella melitensis has been isolated from patients and is thought to have been acquired through contact with small ruminants or as a foodborne infection. To reduce the burden of human brucellosis, the Azerbaijani government began in 2002, a nationwide vaccination control campaign in small ruminants. There is serological evidence of bovine brucellosis (presumably due to Brucella abortus) in Azerbaijan, but no prevalence estimates were available when this study started in March 2017. The aim of this study was to isolate and identify Brucella spp. from cow milk in the Ganja region, where brucellosis takes a heavy toll on humans and livestock.
\end{abstract}

Results: Blood and milk samples were collected from cows $(n=1075)$ in early lactation (up to 90-days) in farms that had a history of previous positive serological results and abortions. Twenty-two out of 57 milk samples collected from seropositive cows, showed growth on Farrell's media, when incubated with $5 \% \mathrm{CO}_{2}$. Eight additional milk samples showed growth in the absence of $\mathrm{CO}_{2}$. The classical biotyping classified them as Brucella abortus (22) and Brucella melitensis (8). RT-PCR confirmed that strains belonged to the genus Brucella. MLVA profiles were obtained for DNA extracted from two B. abortus and six B. melitensis strains. While the B. abortus genetic profile was described in the MLVA database, matching the profile of $B$. abortus strains isolated in East Europe, Central Asia and China, we found a new genotype for the $B$. melitensis strains isolated in Azerbaijan, clustering with strains belonging to the American clade, rarely identified in the region.

Conclusion: Despite the implementation of the vaccination program in small ruminants, our results suggest that spill-over events of $B$. melitensis from small ruminants to cattle have occurred. However, cattle are likely to be primarily infected with $B$. abortus, which warranted the implementation of a bovine brucellosis program. Such a program started in fall 2017. In the Ganja region, cattle should be considered as a potential source of B. abortus and B. melitensis for humans.

*Correspondence: jacques.godfroid@uit.no

${ }^{7}$ Department of Arctic and Marine Biology, Faculty of Biosciences, Fisheries and Economics, UiT - The Arctic University of Norway, Postbox 6050, Langnes, 9037 Tromsø, Norway

Full list of author information is available at the end of the article

\section{Background}

Brucellosis is the most common bacterial zoonosis globally, causing a debilitating human disease $[1,2]$. Human brucellosis is reported worldwide, with at least 500,000 people newly infected annually [3]. Human cases of brucellosis are acquired through contact with infected animals and consumption of contaminated dairy 
products [3]. The decrease in the incidence of human cases depends on developing effective control and eradication programs in cattle and small ruminants $[4,5]$. Among the Brucella species that infect animals, five are known to cause disease in humans, with Brucella abortus, Brucella melitensis and Brucella suis being the most important in terms of clinical severity and prevalence [6]. Brucella melitensis is considered the most prevalent and virulent Brucella species for humans [1]. The human disease typically presents an acute, nonspecific illness characterized by undulating fever, malaise, myalgia, and weight loss that may resemble other acute febrile diseases. A chronic form of brucellosis lasting longer than 12 months after diagnosis can also occur [2, 7]. Brucella infection in women can cause abortions or labor complications and in men, orchitis and epididymitis [7].

Brucellosis in humans was identified in Azerbaijan in 1922 for the first time and was subsequently detected in more than two-thirds of the country's districts over the next 30 years [8]. Of the 62 countries identified as having the highest national incidence of human brucellosis, Azerbaijan currently ranks thirteenth, with an estimated annual human incidence through 2000 at over 50 cases per million $[2,9,10]$. According to a press release issued by the Ministry of Health of Azerbaijan (MoH) in August 2014, approximately 200 human cases of brucellosis were diagnosed in the first 6 months of that year; this detection rate was similar to what was reported in the previous year [11].

Brucella infection in livestock causes significant economic losses through the reduction of productivity. The acute form of the disease are characterized by abortion in pregnant females and orchitis and epididymitis in males, whereas the chronic forms is characterized by hygromas, mainly seen in the tarso-metacarpal joints, inducing lameness in infected animals [12]. The main Brucella species isolated from livestock worldwide are B. abortus, infecting preferentially bovines; $B$. melitensis, infecting preferentially sheep and goats; and B. suis, infecting preferentially pigs $[2,13]$. International veterinary regulations impose restrictions on animal movements and trade in countries that are not "Brucellosis-free," resulting in substantial economic costs due to the implementation of control and eradication programs in cattle and small ruminants worldwide [14].

The collapse of the Soviet Union in 1991 resulted in decreased funding for surveillance and eradication programs in livestock and an increase in human cases. To reduce the burden of human and livestock brucellosis, the Azerbaijani government decided in 2002, to implement a nationwide vaccination control campaign in small ruminants.
Small ruminants are vaccinated against $B$. melitensis with the Rev. 1 vaccine [15]. Female sheep and goats between the ages of 3 and 6 months are vaccinated intraconjunctively, before being moved to summer pasture. Male animals are not vaccinated. In 2016, 6,400,000 heads of small ruminants were vaccinated [16]. At the time our study, cattle were not vaccinated against Brucella spp. [17]. The vaccination with the S-19 vaccine of 3 to 8 month-old cattle started in 2017 [16].

Livestock population estimates for 2020 were about 2.6 million cattle and buffalo, which about 1.2 million were dairy cows and about 77 thousand were dairy buffalo. The small ruminant population comprised about 8 million sheep and about 613,800 goats. There are only about 5700 swine. Livestock numbers have been relatively stable since 2010 [18].

Previous brucellosis studies conducted in Azerbaijan were mainly serological surveys and published information is scarce in the scientific literature. Based on the World Organization for Animal Health (OIE) data for Azerbaijan, brucellosis in cattle, sheep and goats was not reported from 2005 to 2007. Since 2008, data has been annually reported [15]. For instance, 400 - 500 humans, 1100 cattle; and 1200 sheep and goats were found seropositive for brucellosis in Azerbaijan in 2011 [18, 19]. There were 2230 brucellosis cases registered in Azerbaijan in 2017-2018 [15, 16].

When cattle are in contact with infected small ruminants, $B$. melitensis can infect bovines too [20]. Identifying the species of Brucella excreted in milk of dairy cattle is needed to understand the transmission of Brucella spp. within and between cattle herds, as well as between livestock species in mixed (bovines/small ruminants) herds. Importantly, it is also needed to trace back the source of infection of human brucellosis. In case of human infection with $B$. melitensis, the source of contamination can be either small ruminants or bovines. Importantly, the identification of Brucella species in non-preferential hosts (like B. melitensis in bovines), allows to assess if control measures applied in small ruminants are successfully implemented and prevent the transmission of $B$. melitensis from its small ruminant reservoir to cattle.

This study aimed to identify and characterize Brucella species circulating in lactating cattle in brucellosis highrisk villages in the districts serviced by the Goygol Testing Laboratory (RTL). The Goygol district was selected as the site of this study for several reasons, including the extent of livestock production, mixed herding (cattle/ sheep and goat) and use of communal pastures, and the known presence of brucellosis in livestock and humans [21]. Moreover, transhumance is also common practice and the migratory animal population may be at the origin 
of new infections in non-migratory livestock in the Goygol district.

\section{Results \\ Sample collection}

A total of 1075 serum and milk samples were collected from 368 farms between April and August of 2017. Two hundred thirty-three milk and serum samples were collected from Goygol; 120 milk and serum samples were collected from Dashkesen; 160 milk and serum samples were collected from Ganja; 360 milk and serum samples were collected from Goranboy, and 202 serum milk samples were collected from Samukh.

\section{Laboratory testing}

Fifty-seven lactating cows were classified positive by the Rose Bengal Test (RBT). Milk samples from these seropositive animals were cultured on BA with the following results: 54 out of 57 cream samples were culture positive, while 44 out of 57 pellet samples were culture positive. For each milk sample from which the pellet sample was culture positive, the cream sample was also positive. Eight out of 57 milk samples showed growth on BA incubated in a standard incubator, without $\mathrm{CO}_{2}$. These eight isolates showed growth on both Basic Fuschin and Thionin and did not produce $\mathrm{H}_{2} \mathrm{~S}$. For these eight isolates, in the absence of phage typing, a presumptive diagnosis of B. melitensis was obtained. Of note, B. abortus biovar 6 (that has never been isolated in the region) cannot be differentiated from $B$. melitensis, based on the phenotypic tests performed [22]. Thirty (including eight samples that showed growth in the absence of $\mathrm{CO}_{2}$ ) out of 57 milk samples showed growth on BA incubated with $5 \% \mathrm{CO}_{2}$. All isolates were oxidase, catalase, urease positive. Twenty-two isolates that showed $5 \% \mathrm{CO}_{2}$ dependence showed growth on Basic Fuchsin, no growth on Thionin, and produced $\mathrm{H}_{2} \mathrm{~S}$. A presumptive diagnosis of B. abortus was obtained.

All of the isolates were Gram-negative coccobacilli and tested positive by RT-PCR for Brucella spp. Four out of 30 Brucella spp. infected cows had previously aborted, 14 had contact with sheep, 26 had natural and 2 artificial insemination, and 2 were first lactating heifers. Brucella melitensis was isolated from cattle in Goygol, Samukh, and Goranboy districts and Ganja city, while B. abortus was found in all five locations surveyed. A positive sample distribution map is presented in Fig. 1.

\section{Multiple-locus variable number tandem repeat analysis (MLVA) results}

Six isolates growing in the absence of $\mathrm{CO}_{2}$ and two isolates growing exclusively in the presence of $\mathrm{CO}_{2}$ were characterized by MLVA as B. melitensis and B. abortus, respectively.

The six $B$. melitensis strains showed the same genetic profile (3-4-2-13-4-2-3-3-8-36-6-1-4-6-3-6) that was not reported in the MLVA 2020 database. This new genotype is clustering with the genotype of strains belonging to the "Americas" lineage (Fig. 2 and Additional file 1) [23, 24].

When compared to the Brucella MLVA 2020 database, the $B$. abortus strains showed the same genetic profile (4-5-3-12-2-2-3-1-6-43-8-6-4-5-3-3), reported previously (Additional file 2). On the global scale, MLVA-16 assay reveals little diversity of $B$. abortus and suggests an Eurasian distribution of this lineage found in China, Turkey, and Kazakhstan [25].

\section{Discussion}

By carefully selecting animals to be sampled, on the bases of previous epidemiological information and RBT testing, we were able to culture Brucella spp. from cow milk. Standard microbiological biotyping (OIE, 2016) and MLVA confirmed that both B. abortus and B. melitensis were circulating in the cattle population in Azerbaijan.

Globally, Brucella melitensis strains cluster into three main distinct MLVA lineages: the "American", "West Mediterranean," and "East Mediterranean" lineages [23]. Multilocus sequence analysis (MLST) of B. melitensis strains has confirmed the MLVA classification [26]. In 2018, an additional African lineage of B. melitensis was identified [27]. The "American" lineage is also named the "Americas group" or "American clade". It should be emphasized that the American clade, like the African clade are phylogenetic assignments and not geographic ones [27]. Of note, more than $60 \%$ of the isolates of the American clade are of African origin [26].

The B. melitensis strains isolated in Azerbaijan from cattle milk belong to the American lineage. The Rev. 1 vaccine strain belongs to this lineage too [27]. Given the extensive use of Rev.1 in small ruminants in Azerbaijan, it is important to verify that $B$. melitensis strains isolated in cattle are not Rev.1 strains transmitted by vaccinated sheep and goats. The classical biotyping of the six $B$. melitensis strains showed that all strains grew in the presence of Thionin and Basic Fuchsin. Rev.1 does not grow in presence of these dyes. We can therefore exclude that these strains are Rev.1 strains or have evolved from the vaccine strains.

Brucella melitensis strains belonging to the American clade have been previously reported in Asia. Indeed, such strains have been isolated from blue sheep "Bharal" (Pseudois nayaur) in China, typed by MLVA [28] and from human patients in Afghanistan, Syria, Saudi Arabia and Iran, typed by MLST [27]. 


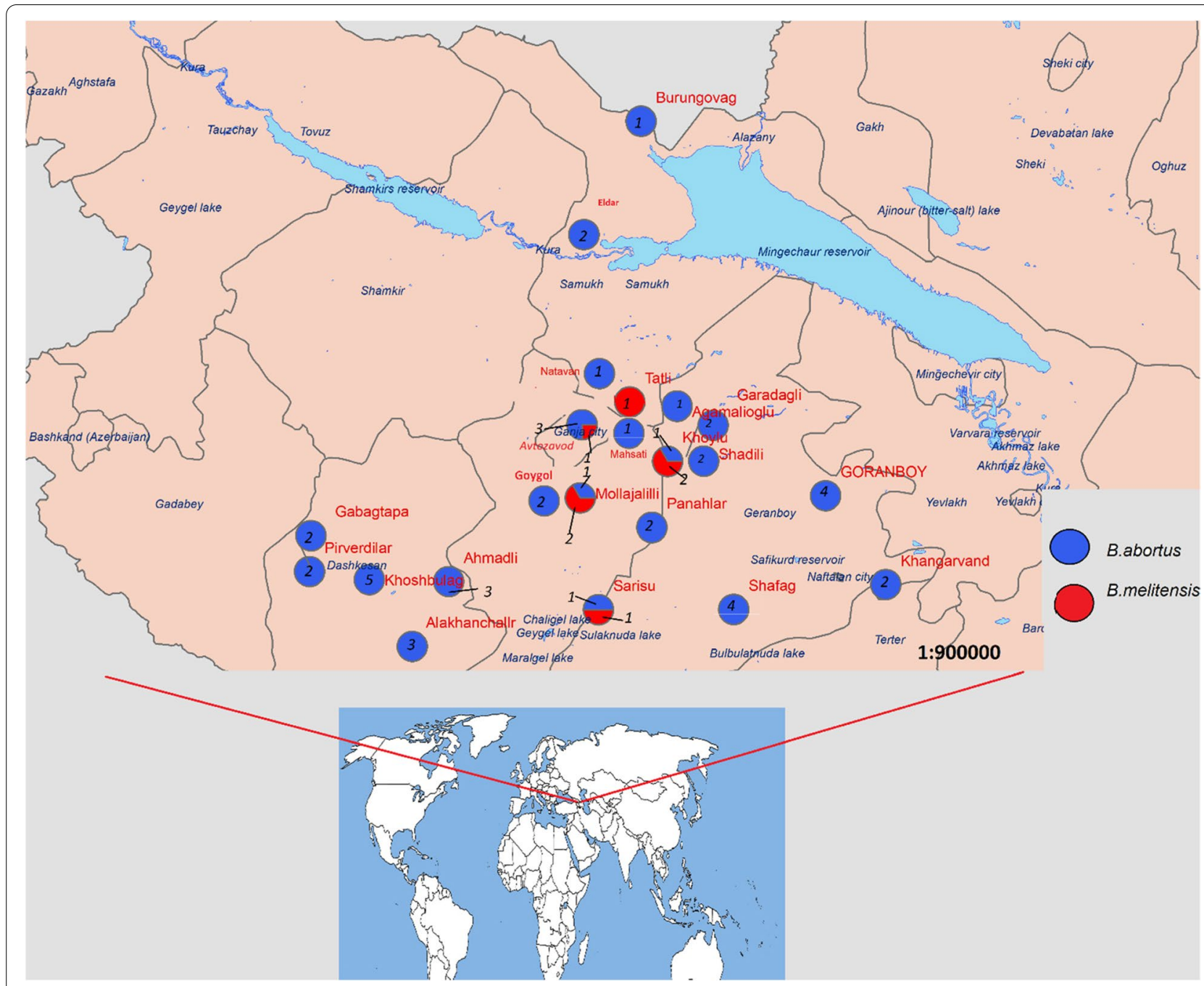

Fig. 1 Location where B. abortus and B. melitensis were isolated. The number in the circle indicates the number of isolated strains from the same location Both B. melitensis and B.abortus were found in 5 villages (Mollajalilli, Sarisu, Avtozavod, Shadli, Khoylu). Only B. abortus was found in 17 villages (Goygol, Panahlar, Eldar, Brungovag, Mehseti, Natavan, Sadili, Khoshbulag, Qabaqtepe, Pirverdi, Alkhanchali Shafag, Agamalioglu, Khan Garvand, Garadagli) while B. melitensis only was found in one village (Tatli)). 3 Brucella spp. were isolated from Mollajalilli out of 3, 2 were B. melitensis, 1 was B.abortus, 2 Brucella spp. were isolated from Sarisu 1 was B.melitensis, 1 was B. abortus. 4 Brucella spp. were isolated from Avtozavod. 3 were B. abortus, 1 was B. melitensis, 5 Brucella spp. were isolated from Shadili. Out of 5, 1 was B. melitensis, 4 were B. abortus, 3 Brucella spp. were isolated from Khoylu. Out of 3, 2 were B. abortus, 1 was B. melitensis. The figure was created using ArcGIS 10.3 (https://desktop.arcgis.com/en/arcmap/10.3/get-started/ installation-guide/installing-on-your-computer.htm)

The MLVA and MLST genotypes of B. abortus show a greater homogeneity than B. melitensis [26]. The MLVA of the two B. abortus strains isolated from cow milk in this study were identical to the MLVA of $B$. abortus strains isolated in China, Turkey, and Kazakhstan [25].

Although brucellosis endemic to Azerbaijan, only a handful of Brucella bacteria have been isolated from human patients. All of these clinical isolates were identified as B. melitensis strains [29]. This suggested that the main reservoir for human transmission was small ruminants. This has been the prevailing assumption in Central
Asia and Eastern Europe [29]. Our study shows that $B$. melitensis can be shed in cattle milk. This suggests that cattle can be the source of human brucellosis due to $B$. melitensis, as it has been shown in France [20]. To date, the isolation of $B$. abortus from human patients has not been reported in Azerbaijan. Nevertheless, our study indicates that B. abortus is shed in cow milk and suggests that humans may be exposed after consumption of cattle milk. When this study was conducted, there was no vaccination program in cattle in Azerbaijan, whereas vaccination of small ruminants with Rev. 1 has been ongoing 


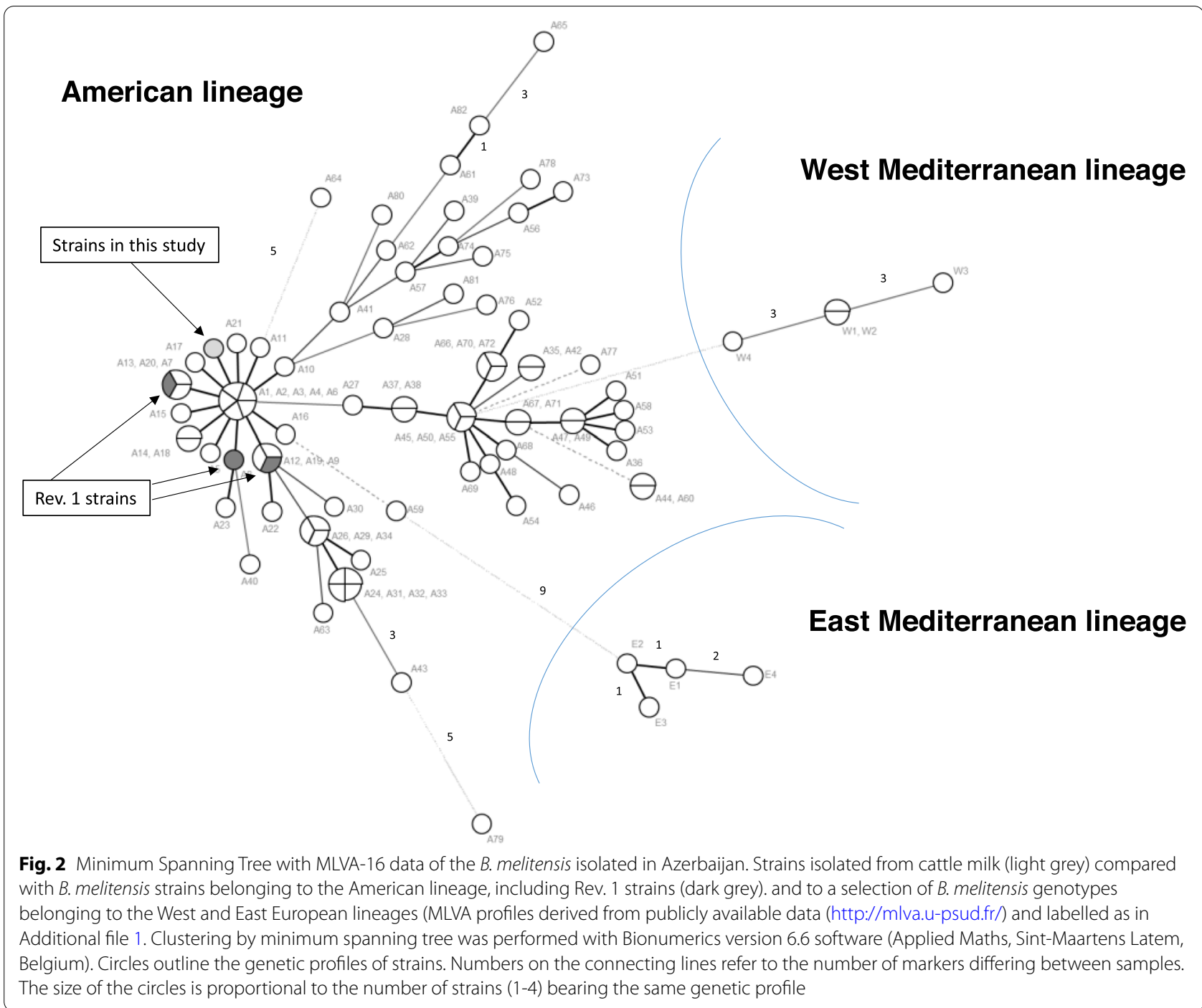

since 2016, when over 6,400,000 heads of sheep and goats were vaccinated [16]. The fact that 6 out of 30 culturepositive cows were excreting $B$. melitensis in their milk, suggests that there are still some foci of $B$. melitensis infection in small ruminants in which transmission to cattle may have occurred. Therefore, a critical evaluation of the Rev.1 vaccination program in small ruminants should be performed. To this effect, antibody titers of vaccinated animals can inform vaccination coverage and efficacy. Studies in Mongolia suggested that $60 \%$ of the small ruminant population should be vaccinated to reach a protective "herd immunity" [30].

Because 14/30 Brucella positive cows were found to be infected with $B$. melitensis, we suggest that $B$. melitensis infected small ruminants remain an important source of cattle infection. To confirm our hypothesis, B. melitensis strains should be isolated from sheep and goats for genetic comparison. Cows excreting $B$. melitensis may further transmit the infection to other bovines and humans. Importantly, the majority of the strains isolated from cow milk are B. abortus. Although B. abortus has not been isolated from human patients, a vaccination program of cattle in Azerbaijan in high-risk areas has been started in 2017.

Our results suggest that the current vaccination campaign in small ruminants should be monitored by performing serology on animals a month after vaccination to assess vaccination coverage and vaccine efficacy. In addition, isolation of $B$. abortus raised the question of whether vaccination against $B$. abortus infection in cattle should be considered.

\section{Conclusion}

This study highlights the importance of strain isolation, identification, and characterization to understand the epidemiology of brucellosis in an endemic situation. 
Indeed, the isolation of $B$. melitensis in a significant proportion ( $>20 \%$ ) out of Brucella spp. excreted in cow milk, suggests that the vaccination campaign against $B$. melitensis in small ruminants has not yet controlled $B$. melitensis circulation in its reservoir species so that $B$. melitensis has spilled over to cattle. Besides, the isolation of B. abortus in a large proportion (>70\%) out of Brucella spp. excreted in cow milk suggests that vaccination of cattle may be warranted.

The isolation of $B$. melitensis from cow milk suggest that strains are circulating between sheep, goats, and cattle in Azerbaijan. The isolation and typing of strains isolated from sheep and goats are needed to establish such epidemiological links. Our MLVA results show that the isolated strains belong to the American clade that is not the dominant clade of $B$. melitensis strains circulating in the region. Indeed, only a handful of strains belonging to the American clade have been isolated in blue sheep in China. Importantly, strains belonging to this clade have been isolated from human patients in the Middle East and Asia. Thus, it suggests that the reservoirs of such strains in livestock may be larger than thought. Indeed, no isolation of strains belonging to the American clade has been reported in neighboring countries, either in sheep and goats or cattle.

The typing of $B$. abortus isolated from cattle milk suggests that strains circulating in Azerbaijan belong to the same clade as strains isolated from East Mediterranean countries to China, suggesting a circulation of strains linked to animal transhumance and trade among these countries.

The vaccination program in sheep and goats needs to be continued in order to stop transmission between sheep and goats, and cattle in Azerbaijan.

The isolation of $B$. abortus provides the Veterinary Authority in the Country with an evidence base information validating its decision to implement $\mathrm{S} 19$ vaccination in cattle, with 398,306 animals (3-8 months of age) being vaccinated in 2017.

Lastly, new techniques such as Whole Genome Sequencing (WGS) applied on strains isolated in the region in different livestock species will help to decipher the epidemiology of animal brucellosis and its transmission to human patients in the future [31].

\section{Methods}

\section{Field activity}

The study was performed in Goygol, Dashkesen, Samukh, Goranboy, and Ganja city. Before the 2017 sample collection, the data on seropositive animals and Brucella high-risk farms in those regions were extracted from the Electronic Integrated Diseases Surveillance System (EIDSS) database [16]. Lactating cows that were not treated with antibiotics during the lactation period were selected for this study. The investigators collected blood and milk samples from cows in early lactation (up to 90-days) in farms that had a history of previous positive serological results and abortions. In addition, lactating first-calf heifers that were likely exposed to Brucella spp., were also sampled. Approximately $5 \mathrm{~mL}$ of blood was collected into serum-separator Vacutainer ${ }^{\circledR}$ (Becton Dickinson, NJ, USA) and $50 \mathrm{~mL}$ of milk into a sterile conical tube. The blood and milk samples were transported to RTL on the day of sample collection.

\section{Serology}

Serum samples were screened using the RBT (Oxoid, Basingstoke, Hants, UK), according to OIE [12].

\section{Bacteriology}

Milk samples that were collected from RBT positive animals were cultured. Milk samples were centrifuged at $3000 \mathrm{rpm}$ for $15 \mathrm{~min}$ at $4{ }^{\circ} \mathrm{C}$. Cream and pellet samples were cultured separately on Brucella agar base no. 2 with Oxoid Brucella selective supplement (Thermo Fisher Scientific, UK), $7 \%$ horse serum, and $1 \%$ glucose and incubated in a standard (without $\mathrm{CO}_{2}$ ) and in a microaerobic $\left(5 \% \mathrm{CO}_{2}\right)$ chamber. Colonies were identified as Brucella spp. through classical identification methods, according to OIE [22].

\section{PCR detection}

DNA was extracted from bacteria grown on Brucella selective media using Qiagen QIAmp DNA Mini (Qiagen, Hilden, Germany). RT-PCR was performed to test for the presence of Brucella spp. using primers and TaqMan probes utilized for the simplex assay (Qiagen, California, USA) as described previously [32]. The quantity of DNA was not assessed.

\section{Multiple-locus variable number tandem repeat analysis (MLVA)}

Genotyping was performed using both minisatellites and microsatellite repeats based on the schemes previously described $[23,33]$. The tandem-repeat loci were divided into three groups: four minisatellite loci in panel 1 (bruce08, bruce12, bruce43, bruce45), two microsatellite loci in panel 2A (bruce18, bruce19) [34].

For the markers bruce08, bruce12, bruce43, bruce 45 , bruce18, bruce19, the PCR product length was defined by capillary electrophoresis with the CEQ 8000 Genetic Analysis System (Beckman Coulter, Indianapolis, IN, USA). The size of each PCR product was then converted to a corresponding tandem repeat number [33]. All data were analyzed using BioNumerics version 6.6 software (Applied Maths, Sint-Maartens Latem, Belgium). 
Clustering analysis was performed using the categorical coefficient and the unweighted-pair group method with arithmetic mean algorithm (UPGMA) as indicated previously [34]. Briefly, three distinct character data sets with different weights were defined according to the markers' diversity index and combined using the composite data set tool provided by BioNumerics. The first one corresponded to panel 1 markers. Each marker of this panel got an individual weight of 2 (total weight for panel 1 : 16). The two others form two groups in panel 2, $2 \mathrm{~A}$ and 2B. Panel 2A markers got a weight of 1 (total weight for panel 2A: 3) and panel 2B markers got a weight of 0.2 (total weight of panel 2B: 1). The MLVA profile of the isolates was also subjected to a minimum spanning tree (MST) analysis, illustrating the diversity existing within the clusters based on single locus variations (SLV). Units (and not sizes) of each marker were considered for the analysis [35].

GPS data was collected during sampling process and ArcGIS 9 (Environmental systems research institute, Redlands, CA, USA) was used to generate the map (Fig. 1).

\section{Supplementary Information}

The online version contains supplementary material available at https://doi. org/10.1186/s12917-022-03155-1.

Additional file 1. MLVA Brucella melitensis lineages 2020 database.

Additional file 2. MLVA Brucella abortus isolated in China, Turkey, Kazakhstan.

\section{Acknowledgments}

We acknowledge the technical assistance and expertise of Veterinary and Agrochemical Research Center in Brussels, Goygol Regional Testing Laboratory, Goygol veterinary office and all the farmers who participated in the study. We thank Dr. Peter Flanagan for initiating this project.

\section{Authors' contributions}

JA, AG, AO and SA contributed the project coordination, data analyses, and manuscript preparation. MA and DF contributed to laboratory analyses and manuscript preparation. JG contributed to conceptualization, project coordination, methodology, data analysis, and manuscript preparation. The authors read and approved the final manuscript.

\section{Authors' information}

Jeyhun Aliyev, MS, DVM, is Deputy Head of the Animal Health Department of the Food Safety Agency of the Republic of Azerbaijan. He has experience in veterinary epidemiology, implements preventive and control measures of animal diseases at the national level, analyzes surveillance data, manages the national electronic surveillance system, carries out appropriate actions to prevent spreading infectious and exotic diseases, and prepares national strategy for eradication of hazardous pathogens. Jeyhun Aliyev is a Ph.D. student at Azerbaijan State Agrarian University. Part of his Ph.D. research he completed at the Arctic Veterinary Medicine at the Norwegian School of Veterinary Science in Troms $\varnothing$ with the support of the university exchange program. Mahnur Alakbarova, BS, DVM, is Director of the Goygol Regional Testing Laboratory under Food Safety Institute. Mahnur Alakbarova has graduated from Azerbaijan State Agrarian University and possesses long years' experience in virology and serology. She participated in more than 30 training sessions on ELISA, RT-PCR, Microbiology techniques conducted by DTRA programs.
Aytan Garayusifova, MS, MPH, PhD, conducted international biomedical and epidemiological research studies on highly pathogenic infectious diseases of bioterrorism potential in collaboration with Walter Reed Army Institute of Research (WRAIR), US and within Biological Threat Reduction Program by Defense Threat Reduction Agency, DoD, US. Currently, pursuing Master's in Public Health at the University of Washington, US, with a focus on infectious disease diagnosis and surveillance and laboratory systems and capacity building.

Asaf Omarov, DVM, MSc, PhD, conducted local and international research studies on infectious diseases specially zoonosis. He has 20 years' experience of research, scientific, academic, field, laboratory and animal health. Asaf Omarov was employed by the Veterinary Laboratory of Ministry of Agriculture (MoA) in Serology, Virology and Epidemiology, and as Head of Laboratory at a poultry farm. He has worked as a Science Coordinator and trainer for the U.S. Defense Threat Reduction Agency's Biological Threat Reduction Program, supporting the implementation of the biosurveillance program in Azerbaijan during 2011-2018. He was Head Department of Animal Husbandry and Welfare at the Ministry of Agriculture in Azerbaijan. Currently, he is Head of Life Science Department at Khazar University and a local consultant of FAO (UN) projects in Azerbaijan.

Saida Aliyeva, PhD, Fulbright Alumni. Dr. Aliyeva possesses 16 years of professional, scientific, and academic experience and training in microbiology and environmental, public, and animal health. Dr. Aliyeva is a 2009-2010 Fulbright Alumni at Chemical Engineering and Bioengineering Department of Washington State University, USA. Saida Aliyeva has worked as a Cooperative Biological Research Coordinator and Science Lead for the U.S. Defense Threat Reduction Agency's Biological Threat Reduction Program, supporting biosurveillance program implementation in Azerbaijan during 2011-2019. Currently, Dr. Aliyeva works for ADA University of Azerbaijan. In parallel, she is an independent consultant of the international and local stakeholders in public and animal health, data analysis, grant writing and project management. She published several publications related to public health, quality assurance, and environmental safety.

David Fretin is the Head of Veterinary Bacteriology Services at Sciensano, the Belgian Institute for Health and Reference Center for Brucella spp. He is contributing in the form of scientific research, expert opinions and service provision to a proactive policy in the area of safety vis-à-vis food production, animal health, particularly zoonoses and emerging infectious diseases which pose a threat to public health, at the level of Belgian and international health. Jacques Godfroid is Professor of Veterinary Microbiology and has specialized in animal disease control, particularly brucellosis. He was member of the task force of the European Union on bovine brucellosis and sheep and goat brucellosis from 2000 to 2004. For the last 10 years he has been working extensively on brucellosis in South-Eastern Africa and Central Asia in a One Health perspective.

\section{Funding}

Open Access funding provided by UiT The Arctic University of Norway We gratefully thank the U.S government Defense Threat Reduction Agency (DTRA) Cooperative Biological Engagement Program in Azerbaijan for technical and financial support with the implementation of the TADR Activity Project "Isolation of Brucella Species from the Milk of Lactating Cattle in High-Risk Villages of the Goygol Region of Azerbaijan" during 2016-2017.

\section{Availability of data and materials}

The datasets analyzed during the current study are available from the corresponding author on reasonable request.

\section{Declarations}

\section{Ethics approval and consent to participate}

This study was reviewed and endorsed by the scientific and technical council of the former State Veterinary Control Services under the Ministry of Agriculture, Azerbaijan.

As blood and milk samples were taken from animals in the field, no ethics committee approval was deemed necessary according to Article 7.1 on recommendations for animal welfare and Article 7.8 on use of animals in research and education of the World Organization for Animal Health Terrestrial Animal Health Code. 
The recruitment of dairy cows into this work was done in consultation with the former State Veterinary Control Services and veterinary practitioners. Milk and blood were collected during routine veterinary practice in adherence to a high standard of veterinary care, and after the permission of the dairy farms' owners. No clinical interventions were performed.

The study was carried out in compliance with the ARRIVE guidelines.

\section{Consent for publication}

U.S government Defense Threat Reduction Agency (DTRA)

\section{Competing interests}

The authors declare that they have no competing interests.

\section{Author details}

'Department of Epizootology, Microbiology and Parasitology, Faculty of Veterinary Medicine, ASAU - Azerbaijan State Agricultural University, 450, Ataturk Avenue, AZ 2000 Ganja, Azerbaijan. ${ }^{2}$ Goygol Regional Testing Laboratory, Azerbaijan Food Safety Institute, Heydar Aliyev Ave. 142, Goygol, Azerbaijan. ${ }^{3}$ Department of Epidemiology, School of Public Health, UW - The University of Washington, 1959 NE Pacific St, Seattle, WA, USA. ${ }^{4}$ Life Science Department, Khazar University, 41 Mehseti Street, AZ1096 Baku, Azerbaijan. ${ }^{5}$ Black \& Veatch Special Projects Corp, Maryam Plaza, 12 B.Baghirova, AZ1065 Baku, Azerbaijan. ${ }^{6}$ Sciensano, Veterinary Bacteriology, Groeselenberg 99, 1180 Brussels, Belgium. ${ }^{7}$ Department of Arctic and Marine Biology, Faculty of Biosciences, Fisheries and Economics, UiT - The Arctic University of Norway, Postbox 6050, Langnes, 9037 Tromsø, Norway.

\section{Received: 12 August 2021 Accepted: 17 January 2022}

Published online: 15 February 2022

\section{References}

1. Alton GG, Mickley R, RU NY. The epidemiology of Brucella melitensis infection in sheep and goats. Curr Top Vet Med Anim Sci (Países Bajos). 1985; https://agris.fao.org/agris-search/search.do?recordID=XL20120022 32.

2. Pappas G, Papadimitriou P, Akritidis N, Christou L, Tsianos EV. The new global map of human brucellosis. Lancet Infect Dis. 2006;6(2):91-9. https://doi.org/10.1016/S1473-3099(06)70382-6.

3. Corbel MJ. Brucellosis in humans and animals: World Health Organization; 2006. ISBN 9789241547130

4. Freitas LV, Teles LM, Lima TM, Vieira NF, Barbosa RC, Pinheiro AK, et al. Exame físico no pré-natal: construção e validação de hipermídia educativa para a Enfermagem. Acta Paulista de Enfermagem. 2012;25(4):581-8. https://doi.org/10.1590/s0103-21002012000400016.

5. Minas A, Minas M, Stournara A, Tselepidis S. The "effects" of Rev-1 vaccination of sheep and goats on human brucellosis in Greece. Prev Vet Med. 2004;64(1):41-7. https://doi.org/10.1016/j.prevetmed.2004.03.007.

6. Godfroid J, Scholz HC, Barbier T, Nicolas C, Wattiau P, Fretin D, et al. Brucellosis at the animal/ecosystem/human interface at the beginning of the 21st century. Prev Vet Med. 2011;102(2):118-31. https://doi.org/10.1016/j. prevetmed.2011.04.007.

7. Evans AS. Epidemiological concepts. In: Bacterial infections of humans. Boston: Springer; 2009. p. 1-50. https://doi.org/10.1007/ 978-0-387-09843-2_1.

8. Gurbanov S, Akhmedova S. Especially dangerous infections in Azerbaijan. In: Emerging and endemic pathogens. Dordrecht: Springer; 2010. p. 39-43. https://doi.org/10.1007/978-90-481-9637-1_5.

9. Manaseki S. Mongolia: a health system in transition. BMJ. 1993;307(6919):1609. https://doi.org/10.1136/bmj.307.6919.1609.

10. Abdullayev R, Kracalik I, Ismayilova R, Ustun N, Talibzade A, Blackburn JK. Analyzing the spatial and temporal distribution of human brucellosis in Azerbaijan (1995-2009) using spatial and spatio-temporal statistics. BMC Infect Dis. 2012;12(1):1-2. https://doi.org/10.1186/1471-2334-12-185.

11. Azernews.az. Baku: Brucellosis, a serious disadvantage of hot summer. Press Release. Available from: https://www.azernews.az/nation/69597. html. Accessed 1 Mar 2021

12. OIE. Brucellosis (Brucella abortus, B. melitensis and B. Sui)(infection with B. abortus, B. melitensis and B. suis). In: Manual of diagnostic tests and vaccines for terrestrial animals; 2016. p. 1-44. https://www.oie.int/en/ what-we-do/standards/codes-and-manuals/terrestrial-code-onlineaccess/index.php?id=169\&L=1\&htmfile=chapitre_bovine_brucellosis. htm.

13. Doyle KA, Gordon H. Merck veterinary manual. Aust Vet J. 1993;70(7):278. https://doi.org/10.1111/j.1751-0813.1993.tb08058.x.

14. Caminiti A, Pelone F, Battisti S, Gamberale F, Colafrancesco R, Sala M, et al. Tuberculosis, brucellosis and leucosis in cattle: a cost description of eradication programmes in the region of Lazio, Italy. Transbound Emerg Dis. 2017;64(5):1493-504. https://doi.org/10.1111/tbed.12540.

15. OIE - World Organisation for Animal Health. The World Animal Health Information System. 2015. Available from: https://wahis.oie.int/\#/ report-smr.

16. Electronic Integrated Disease Surveilance System -EIDSS. Baku; 2014. Available from https://web.eidss.az.

17. Aliyev J. Isolation of Brucella species from the milk of lactating cattle in high risk villages of the Goygol region of Azerbaijan 2017: State Veterinary Control Service under Ministry of Agriculture of Azerbaijan Republic; 2017. p. 34. Final report AJ-TAP 12

18. The State Statistical Committee of the Republic of Azerbaijan. Number of farm animals. 2010. Available from: https://azstat.org/statHtml/statHtml. do?orgld=994\&tblld=DT_BB_004\&conn_path=12\&language=en.

19. Omarov AM, Jackson R, Brant J, et al. The new brucellosis surveillance system in Azerbaijan. Buenos Aires: Brucellosis International Research Conference; 2011. p. 90. https://www.aam.org.ar/brucellosis2011/desca rgas/brucellosis2011-argentina.pdf

20. Verger JM, Garin-Bastuji B, Grayon M, Mahé AM. Bovine brucellosis caused by Brucella melitensis in France. Ann Vet Res. 1989;20(1):93-102 https:// pubmed.ncbi.nlm.nih.gov/2930137/.

21. Shabandayeva A. lunfluence of erosion prosess in the north and east part of Small Caucasus on ecological situation and ecosystem and necessity of taking complex control measures against it; 2011. p. 144. http://anl.az/ el/alf25/sha_kqsvss.pdf

22. OiE-World Organisation for Animal Health. Bovine brucellosis. OiE terrestrial manual. 2009. http://www.oie.int/fileadmin/Home/eng/Health_ standards/tahm/2008/pdf/2.04.03_BOVINE_BRUCELL.pdf. Accessed 6 Nov 2020.

23. Al Dahouk S, Nöckler K, Scholz HC, Pfeffer M, Neubauer $\mathrm{H}$, Tomaso $\mathrm{H}$. Evaluation of genus-specific and species-specific real-time PCR assays for the identification of Brucella spp. Clin Chem Lab Med. 2007;45(11):146470. https://doi.org/10.1515/cclm.2007.305.

24. Ferreira AC, Chambel L, Tenreiro T, Cardoso R, Flor L, Dias IT, et al. MLVA16 typing of Portuquese human and animal Brucella melitensis and Brucella abortus isolates. PLoS One. 2012;7(8):e42514. https://doi.org/10.1371/ journal.pone.0042514.

25. Shevtsova E, Shevtsov A, Mukanov K, Filipenko M, Kamalova D, Sytnik I, et al. Epidemiology of brucellosis and genetic diversity of Brucella abortus in Kazakhstan. PLoS One. 2016;11(12):e0167496. https://doi.org/ 10.1371/journal.pone.0167496.

26. Whatmore AM, Koylass MS, Muchowski J, Edwards-Smallbone J, Gopaul KK, Perrett LL. Extended multilocus sequence analysis to describe the global population structure of the genus Brucella: phylogeography and relationship to biovars. Front Microbiol. 2016;7:2049. https://doi.org/10. 3389/fmicb.2016.02049.

27. Foster JT, Walker FM, Rannals BD, Hussain MH, Drees KP, Tiller RV, et al. African lineage Brucella melitensis isolates from Omani livestock. Front Microbiol. 2018;8:2702. https://doi.org/10.3389/fmicb.2017.02702.

28. Jiang $H$, Wang $H, X u L, H u G, M a J$, Xiao $P$, et al. MLVA genotyping of Brucella melitensis and Brucella abortus isolates from different animal species and humans and identification of Brucella suis vaccine strain S2 from cattle in China. PLoS One. 2013;8(10):e76332. https://doi.org/10. 1371/journal.pone.0076332.

29. PuertoYury K, Kulakov MMZ. Use of molecular methods for species and strain typing of Brucella isolates to improve brucellosis surveillance in Russia: Brucellosis 2011 - International Research Conference; 2011. p. 25. https://www.aam.org.ar/brucellosis2011/descargas/brucellosis2011argentina.pdf

30. FAO. Regional workshop on brucellosis control in Central Asia and Eastern Europe. In: FAO animal production and health report no. 8. Rome; 2015. p. 32. http://www.fao.org/3/i4387e//4387E.pdf.

31. Tan KK, Tan YC, Chang LY, Lee KW, Nore SS, Yee WY, et al. Full genome SNP-based phylogenetic analysis reveals the origin and global spread of 
Brucella melitensis. BMC Genomics. 2015;16(1):1-1. https://doi.org/10. 1186/s12864-015-1294-x.

32. Probert WS, Schrader KN, Khuong NY, Bystrom SL, Graves MH. Real-time multiplex PCR assay for detection of Brucella spp., B. abortus, and B. melitensis. J Clin Microbiol. 2004;42(3):1290-3. https://doi.org/10.1128/ jcm.42.3.1290-1293.2004.

33. Le Flèche P, Jacques I, Grayon M, Al Dahouk S, Bouchon P, Denoeud F, et al. Evaluation and selection of tandem repeat loci for a Brucella MLVA typing assay. BMC Microbiol. 2006;6(1):1-4. https://doi.org/10.1186/ 1471-2180-6-9.

34. Garofolo G, Di Giannatale E, De Massis F, Zilli K, Ancora M, Cammà C, et al. Investigating genetic diversity of Brucella abortus and Brucella melitensis in Italy with MLVA-16. Infect Genet Evol. 2013;19:59-70. https://doi.org/ 10.1016/j.meegid.2013.06.021

35. Hanot Mambres D, Boarbi S, Michel P, Bouker N, Escobar-Calle L, Desqueper D, et al. Imported human brucellosis in Belgium: bio and molecular typing of bacterial isolates, 1996-2015. PLoS One. 2017;12(4):e0174756. https://doi.org/10.1371/journal.pone.0174756.

\section{Publisher's Note}

Springer Nature remains neutral with regard to jurisdictional claims in published maps and institutional affiliations.

- fast, convenient online submission

- thorough peer review by experienced researchers in your field

- rapid publication on acceptance

- support for research data, including large and complex data types

- gold Open Access which fosters wider collaboration and increased citations

- maximum visibility for your research: over $100 \mathrm{M}$ website views per year

At BMC, research is always in progress.

Learn more biomedcentral.com/submissions 